\title{
The IMOSMID project: increasing energy efficiency by identification, assessment and use of eco-friendly technologies and management plans for public and private transport
}

\author{
L. Buzzoni ${ }^{1,2}$ \\ ${ }^{1}$ Mobility and Public Transport Department, \\ DG Infrastructural Networks, Logistics and Mobility Systems, \\ Emilia-Romagna Region, Italy \\ ${ }^{2}$ DIENCA (Department of Energy, Nuclear and Environmental Protection \\ Engineering), Faculty of Engineering, Bologna University, Italy
}

\begin{abstract}
The European Project IMOSMID (Integrated MOdel for Sustainable Management of Mobility in Industrial Districts) is strongly focused on energy efficiency and carbon saving issues, showing new technologies and devices (fuel cells, charging points from RE, etc.) which could facilitate the introduction of electrical vehicles not only for the inner cities, but also for metropolitan areas, improving its features through the increase of autonomy and availability of the vehicle. IMOSMID aims at reducing carbon emissions by identification, assessment and exchange of innovative technologies and management plans for sustainable transport, by strongly focusing on energetic aspects as well as taking into account environmental and sanitary aspects. The identification of optimal management models for people mobility in productive areas will serve to reduce individual and private car usage for the home-work commuting with dedicated measures particularly related to carpooling.
\end{abstract}

Keywords: energy efficiency, mobility management, innovative technologies, renewable energy, carbon emissions. 


\section{Introduction}

Balancing mobility with its costs and harms has become a paramount challenge of this century. A large majority of European citizens live in an urban environment, with over 60\% living in built-up areas of over 10,000 inhabitants. Congestion, poor air quality and noise exposure principally affect urban areas. Urban mobility accounts for about a quarter of $\mathrm{CO}_{2}$ emissions from transport, and almost $70 \%$ of road accidents take place in cities. In the EU, transport depends on oil and oil products for more than 96\% of its energy needs. Europe imports around $84 \%$ of its crude oil from abroad. Despite the efforts to increase transport efficiency, transport greenhouse gas emissions, including those from international aviation and maritime transport, increased by around 34\% between 1990 and 2008. For comparison, over the same period, energy industries reduced their emissions by about $9 \%$. Transport is responsible for about a quarter of the EU's greenhouse gas emissions. $71.3 \%$ of overall emissions are generated by road transport (2008) [1]. One major reason for the failure to curb transport emissions and related negative effects is that transport demand increase is stronger than transport energy efficiency improvements. Most transport improvements were actually targeted at increasing existing transport capacities, removing bottlenecks as well as increasing transport speed which in turn generated new demand. So far, EU policy has been very successful in developing and improving the supply side of transport: in particular, infrastructure, transport systems and logistics. But if the transport $\mathrm{CO}_{2}$ emission reduction of $60 \%$ is to be met by 2050 then it is inevitable to work on both sides: making transport supply more energy-efficient while decreasing transport demand, thus making the entire system more energy efficient and thus closer to carbon-neutral. That latter point is not undisputed, as there is an association between economic growth and the growth in transport activity. However, at least in the case of person transport, it is not obvious that a higher number of passenger $\mathrm{km}$ is required to sustain economic growth: while a person is driving a car, he/she neither produces goods and services, nor does she/he buy or consume, except for petrol. Further, driving in urban environments is stressful. Employees arriving stressed at their work places have a lower productivity. In Economic terms, transport is well known as a derived demand, meaning that people travel for a certain purpose, such as work, study, shopping or recreation, but it is unusual to travel solely for the purpose of traveling. If transport is not the primary goal but is responsible for many negative impacts, then travelling should be minimized where possible, and further, wherever traveling takes place, its impacts should be minimized. Identifying opportunities for improvements and evaluating best practice applications that respect the socio-economic diversity of European regions is at the heart of the IMOSMID project. The industrial settlements positioned outside the metropolitan environment, especially in National and Local Functional Urban Areas (FUA), as defined by the European Commission within the framework of the European Program (ESPON), represent remarkable areas generating and attracting home-work mobility. Public infrastructures and transport services offer for employees coming from residential zones are often 
inadequate: it depends on the fact that residential areas are spread across the entire territory; therefore the creation of a public transportation network with adequate coverage proves complex and expensive. A European experience in this field is given by the Life Project Gesmopoli in Barcelona, Spain, focused on the activation of planning policies between social partners rather than on supply and coordination of supplementary transport services, in addition to public transport system. The aim of IMOSMID project is to identify and define an innovative integrated governance model inspired by criteria for sustainable mobility. In this way it will be possible to satisfy the growing demand of additional /complementary LPT (Local Public Transport) services and the reduction of the use of private vehicles and resulting externalities. Moreover a featuring element of this project matching the transport themes/topics with energy matters/features by a system enable the use energy produced through renewable sources within a testing territorial district. There are two different modes to choose between with concrete potential for reducing transportation impact, namely improving behavioural change of citizens in favor of more sustainable transport modes and to reduce the negative impacts of existing modes. In some cases the above approaches are not clearly separable, as new technologies do also require a change of habits. A strong European focus has been addressed on improving the supply side of transport which has shown negative effects over the past decade: despite the great potentials of future propulsion technologies, it needs to be recognized that transport is more than efficiency, capacity and speed. Transport is a part of everyone's daily experience, and people organize their lives around the transport options being offered. The interaction between supply and demand results in the overall usage of transport systems. The focus of the EU on developing new transport technologies is justified as to increase Europe's industrial competitiveness, a strategic sector. On the other hand, in terms of $\mathrm{CO}_{2}$ reduction, it may turn out to be equally important to export European low carbon lifestyles, especially to those countries which cannot afford the latest technologies but are in an urgent need for solutions for their fast growing economies and populations. The avoidance of trip generation is very effective, as a trip that does not take place has zero impact and requires zero resources. Avoidance of trip generation also has a social benefit, in particular for elderly people and those with disabilities, who may have problems about travelling. Time not spent travelling has potential to be invested in more useful ways, from social involvement to economic productivity. There has been a series of activities and improvements over time, yet systematic trip generation avoidance has not been the focus of EU research, despite its potential.

\section{The IMOSMID project and its goals}

The question of how to enhance mobility, while at the same time reducing congestion, accidents and pollution, remains a common challenge for all major cities in Europe. Some solutions are forthcoming through the effective adoption of the White Paper: Roadmap to a Single European Transport Area - Towards a competitive and resource efficient transport system. The IMOSMID project's 
aim of contributing to the reduction of $\mathrm{CO}_{2}$ emissions related to urban transport is fully in line with this White Paper, and the valuable lessons learned that it offers are extremely welcome as a useful resource for technicians and policymakers. IMOSMID aims at lowering carbon output of urban transport through the use of innovative sustainable technologies coupled with demand management. The IMOSMID goal is to identify, assess and share effective methods and models. IMOSMID hopes to thus foster public sector strategies for optimising the effectiveness of sustainable transport solution adoption. This broad goal is comprised of numerous approaches. As cited above, there has been a strong European focus on improving the supply side of transport which has shown negative effects over the past decade. Despite the great potentials of future propulsion technologies, it needs to be recognized that transport is more than efficiency, capacity and speed. Transport is a part of everyone's daily experience, and people organize their lives around the transport options being offered. The interaction between supply and demand results in the overall usage of transport systems. The focus of the EU on developing new transport technologies is justified as to increase Europe's industrial competitiveness, a strategic sector. On the other hand, in terms of $\mathrm{CO}_{2}$ reduction, it may turn out to be equally important to export European low carbon lifestyles, especially to those countries who cannot afford the latest technologies but are in an urgent need for solutions for their fast growing economies and populations. This is why IMOSMID is examining the whole spectrum of options, which include both, the transport supply side as well as transport demand side. All transportation modes consume energy and today this is mostly derived from the combustion of oilderived fuels and, in general, of hydrocarbons. Combustion inevitably produces $\mathrm{CO} 2$ and a lot of other substances, depending on specific fuel characteristics, e.g. Nitrogen Oxides, Sulphur Oxides, Lead (Pb), Volatile Organic Compounds (VOCs), Particulate Matter (PM), and Carbon Monoxide (CO) due to incomplete combustion. At certain concentrations, such substances change physical and biological characteristics of the air (mainly of the troposphere) with adverse consequences on health, climate and weather precipitations. Most of the noxious emissions stay in a small range from the source. Some of them spread further such as $\mathrm{CO}_{2}$, NOx and $\mathrm{SO}_{2}$, producing effects in other regions. In order to reduce traffic air pollution, RER (Emilia-Romagna Region) allocates incentives to local public transport (LPT) either by contributing to the bus fleet renewal or by supporting researches, meetings and agreements, collaborating for this purpose with the Department of Energy, Nuclear and Environmental Protection Engineering (DIENCA) of University of Bologna, that strives to promote and coordinate basic and applied research relating to the processes of rational usage of energy sources. For this purpose RER works together with national and regional research institutes such as Cnr, Arpa and ENEA. RER's strategy aims on one side at progressively creating local public transport fleets made up of ecocompatible vehicles, and on the other side - in relationship to urban areas - at supporting modal interchange and traffic fluidification on the main access roads to towns centres (by means of reserved bus lanes and telecontrol systems). 


\subsection{Actions and methods pursued}

The European Project IMOSMID (Integrated MOdel for Sustainable Management of Mobility in Industrial Districts), with reference to the related Emilia-Romagna Region Partner's role, will pay particular emphasis on study of opportunities, synergies and benefits for implantation of fleets of pure batteries electric vehicles charged from renewable energy facilities, both for private and public use in productive areas specifically qualified as Industrial Districts, according to population, territory, environment, social customs, climatology, etc. In this point, the project is strongly focused on energy efficiency and carbon saving issues, showing new technologies and devices (fuel cells, charging points from RE, etc.) which could facilitate the introduction of electrical vehicles not only for the inner cities, but also for metropolitan areas, improving its features through the increase of autonomy and availability of the vehicle.

Thanks to electrical vehicles in the future it will be possible to achieve urban vehicles with local zero-emissions and no compromise in performance.

In the case of greenhouse gases, effects take place at planetary level. It is important to observe that large differences arise in global (well-to-wheel) $\mathrm{CO}_{2}$ emissions for electric and non-electric transport.

The organisational/management approach of the Project follows the below illustration (Fig. 1), the Partnership is between: Province of Reggio-Emilia as Project Leader, Emilia-Romagna Region, Reggio Emilia's Local Mobility Agency (ACT), the Municipality of Correggio, En. Cor (Correggio Energy Company), Diputaciò de Barcelona into the role of Associated Beneficiaries:

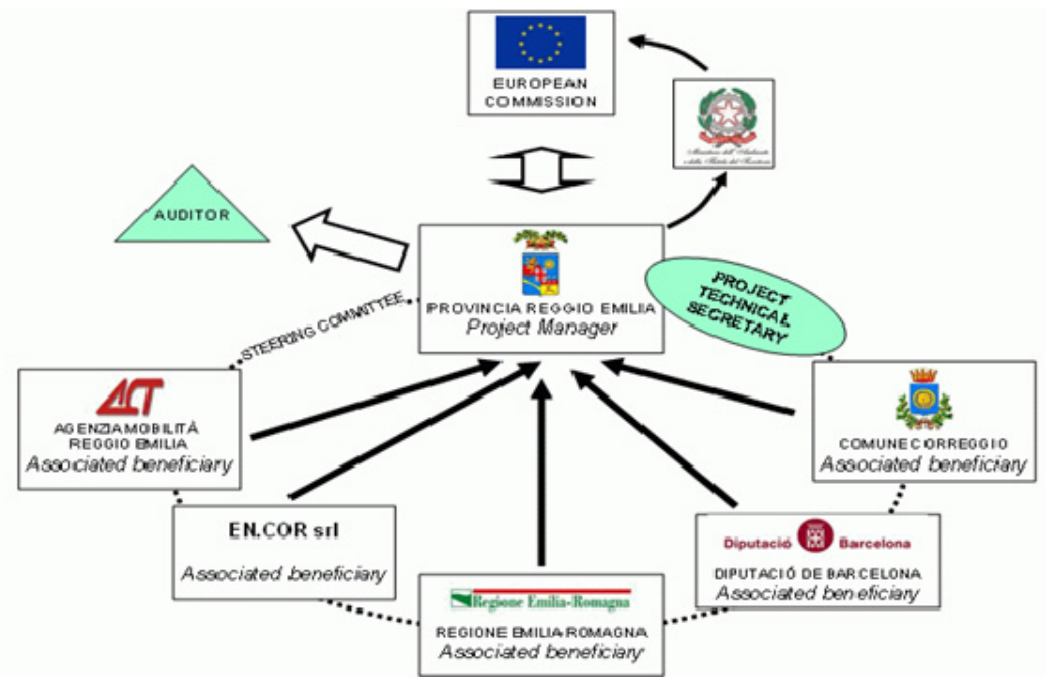

Figure 1: $\quad$ Organisational/management scheme of IMOSMID Project. 
Further paramount aspects of the project are:

- The Project has been co-financed by the European Programme LIFE + 2009 - Action Environmental Policy and Governance (3rd in ranking);

- Duration: started the 1st September 2010 and ends on 31st August 2013, lasting for a period of three years;

- Co-financing: European funding is $€ 820.783,00$, which covers nearly the $46 \%$ of total value of planned actions, amounting to $€ 2,166,566.00$.

The Province of Reggio Emilia is a typically industrial province with a widespread and deeply rooted entrepreneurial tradition, especially small and medium sized enterprises: likewise the rest of the Emilia-Romagna region, the industrial sector is organized in so called “industrial districts”. More specifically, Correggio has various productive sectors, with many excellences, especially in the following three main areas: Mechanical engineering, Plastics and Textiles, as shown in the figure below (Fig. 2):

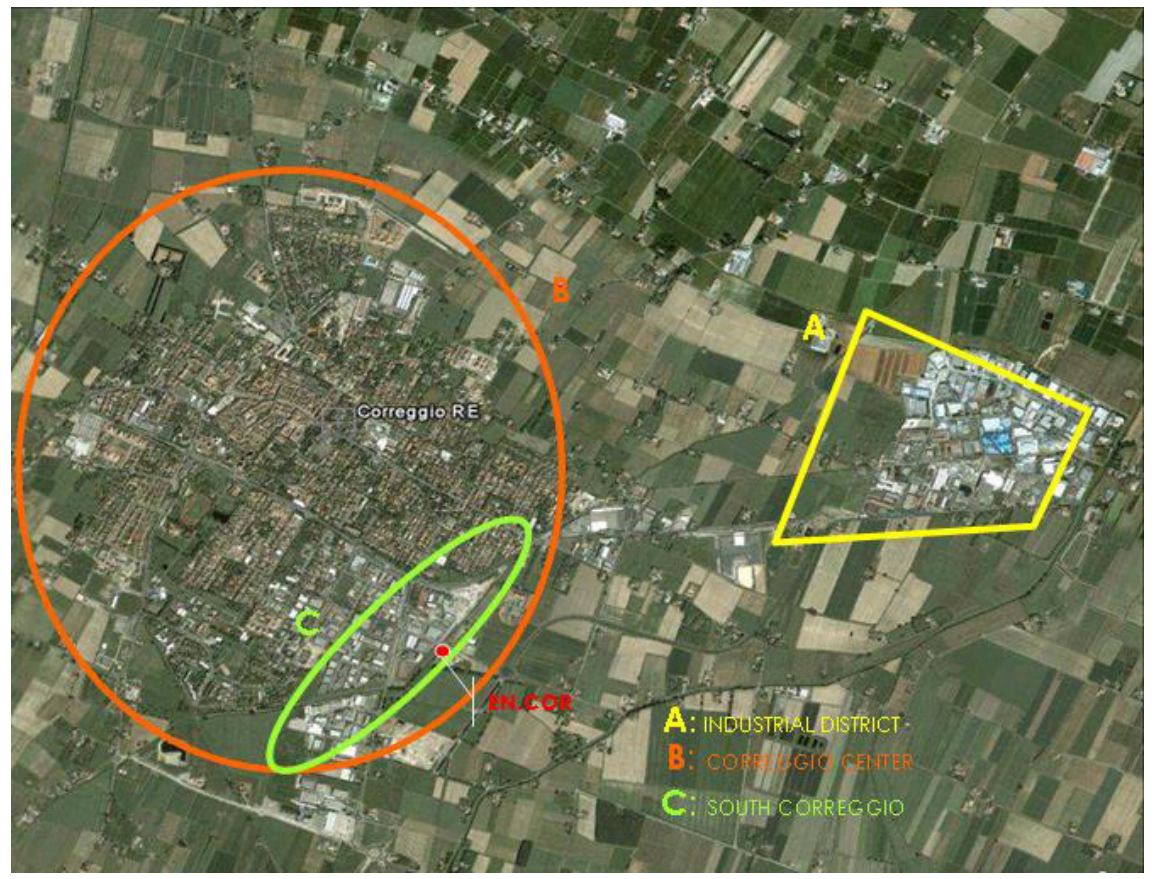

Figure 2: $\quad$ Industrial districts of Correggio and related productive sectors.

IMOSMID aims at reducing carbon emissions by identification, assessment and exchange of innovative technologies and management plans for public and private transport. This entails the development of public sector strategies for optimising the design and delivery of sustainable transport solutions, comprising several approaches like the identification of innovative and eco-friendly technologies suitable to be used in urban areas both in public and private transport, realistic assessment of impacts, benefits, costs and requirements for 
infrastructure and supply chains, barriers and gaps, R\&D and Innovation priorities. The Project is strongly focusing on energetic aspects of sustainable transport, as well as is taking into account environmental and sanitary aspects. The main themes and sub-themes influenced by IMOSMID Project are energy efficiency, renewable energy and fuels, sustainable transport and behaviour change. The project will pay particular emphasis on:

a. the identification of optimal management models for people mobility based on sustainability criteria and the development of an innovative and integrated approach for the Mobility Management in productive areas specifically qualified as Industrial Districts, including in these models the study of opportunities, synergies and benefits for implantation of mixed fleets of pure batteries electric vehicles, charged from renewable energy facilities. In this specific point, the project is strongly focused on energy efficiency and carbon saving issues, showing new technologies and devices (charging points from RE, etc.) which could facilitate the introduction of electrical vehicles not only for the inner cities, but also for metropolitan areas, improving its features through the increase of autonomy and availability of the vehicle;

b. reducing the use of private transport to travel to major traffic attractors while at the same time encouraging the use of group transport and other means of transport associated with a low-level environmental impact;

c. the promotion of the Shifting-Mode and the Modal-Split, to face the growing demand for transports, from private to local public transports, and notably to zero emissions vehicles: in order to save energy and reduce at the same time local $\mathrm{CO}_{2}$ emissions;

d. the integration of transport and energy in a system capable of taking advantage from renewable energy produced within the industrial districts of the Municipality of Correggio, to support the local transport policy of sustainability.

The Integrated Model of Sustainable Mobility Management in the industrial districts will be developed through: i) the establishment of a coordination structure (Office of District Mobility Management); ii) the activation of carpooling services; iii) the activation of innovative services (i.e. on demand transports through the use of hybrid buses - electric power and natural gas/diesel clean). The interaction among the several planned actions will follow the below scheme (Fig. 3), articulated in 20 different actions:

\section{Preparatory actions}

Action 1 - Analysis of demand and actual house-work mobility system (Province of Reggio-Emilia);

Action 2 - Analysis of European best practices (Barcelona);

Action 3 - Planning of innovative services (ACT);

Action 4 - Planning of District Mobility Management Office (ACT);

Action 5 - Definition of technical requirements for the production of renewable energy by autotraction (En. Cor);

Action 6 - Arrangement with and involvement of the stakeholders (Correggio). 


\section{Activation actions}

Action 7 - Activation of District Mobility Management Office, organization and management of services (ACT);

Action 8 - Promotional Services Plan (Province);

Action 9 - Creation of a suppliers' network for the sustainable mobility ticket (Province);

Action 10 - Realization of a plan for renewable energy production and related infrastructures (En. Cor);

Action 11 - Activation of energy production plan and energy supply (En. Cor).

\section{Accompanying actions}

Action 12 - Project Management;

Action 13 - Monitoring (in progress and ex-post) and evaluation of efficiency;

Action 14 - External Audit.

\section{Communication and diffusion actions}

Action 15 - Dissemination actions at local-regional level (Emilia-Romagna Region);

Action 16 - Dissemination actions at national - European level (EmiliaRomagna Region);

Action 17 - Website (Province of Reggio Emilia);

Action 18 - Information Panels (Emilia-Romagna Region);

Action 19 - Final Guidelines (Province of Reggio Emilia);

Action 20 - After LIFE Communication Plan (Province of Reggio Emilia).

The preparatory actions performed during the last year allowed to focus the state-of-art of the "home-work" mobility problems and to define detailed and targeted solutions, taking into consideration the needs of employees and the main social partners, starting from the most advanced experiences at European level.

At the same time technological requirements for renewable energy production by auto-traction have been in depth investigated. By succeeding in the previous actions described above, the activation actions represent the concrete realization of the Preparatory Phase with the purpose of start and experiment the new Mobility Management System and create the conditions that will make this system fully sustainable in all respects. The Local Agency for Mobility will provide the staff for the District Mobility Management Office, supported by the central staff for administrative activities. An educational and formative training and an external support will be guaranteed to the operating staff. EmiliaRomagna Region will acquire the software in order to manage properly the carpooling services organization and the transport on call. In the project life-time the website will be the main tool for communication, coordination and informative support, used by all involved actors. Other promotional measures will consist in direct marketing, promotional campaign in the local media, meetings at the companies, diffusion on other European and National funded projects. Financial resources necessary for the realization of the plant, structure for handle operation and maintenance will be assured by En. Cor internal resources. The accompanying actions include: technical control over the progress along all phases, different partners coordination Steering Committee 
organization, supervision of technical benefits and project progress, periodical reporting to the Commission and financial management of the project.

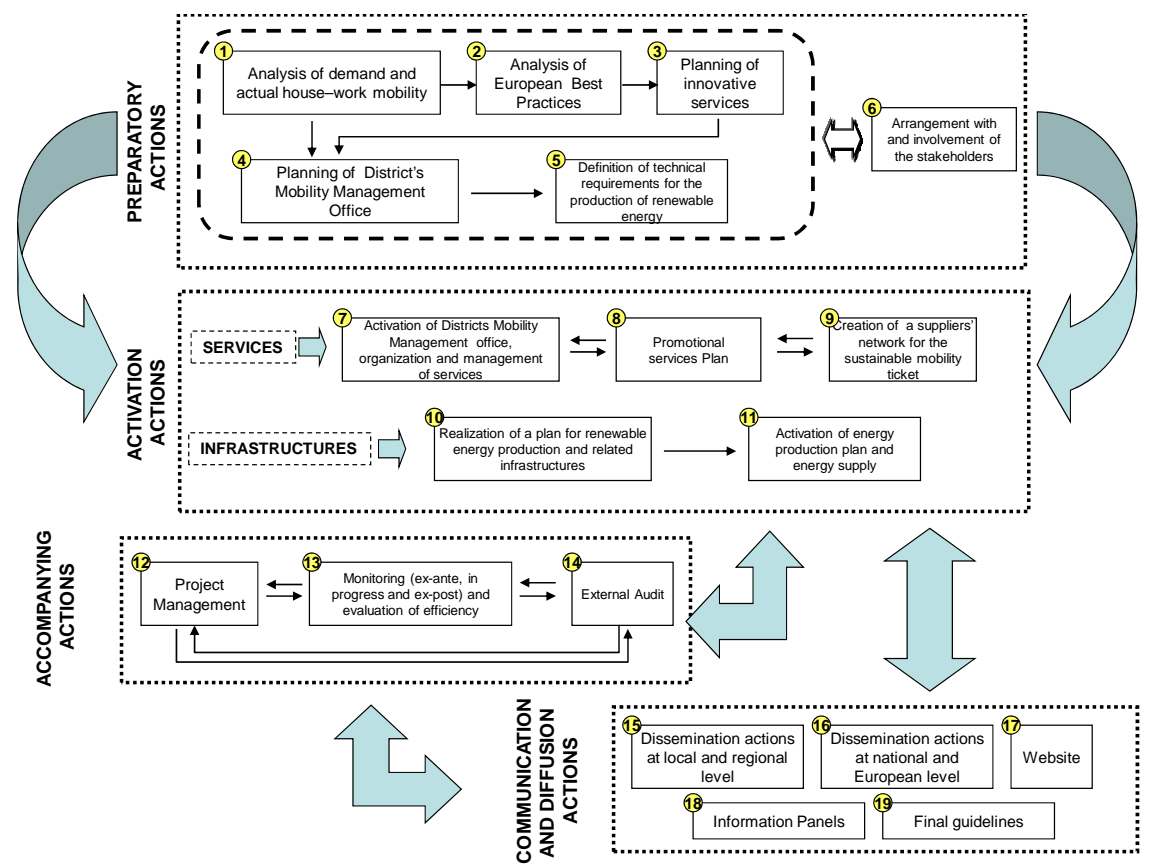

Figure 3: $\quad$ Scheme of interrelationships among the various project actions.

The communication and diffusion actions play a determinant central role in the project representing a twofold objective: first of all raising awareness among all the stakeholders to the ongoing initiatives and on the other side to promote and disseminate the new Mobility Management's Model in the Functional Urban Areas on both local and European level. The participation activities with regards to stakeholders consist of three steps: 1) interviews with testimonials of excellence; 2) forum plenary presentation of the project; 3) thematic forums with key stakeholders. The conducted interviews with testimonials of excellence allowed:

- $\quad$ to provide detailed information on the project;

- $\quad$ to analyze in depth what are the strengths and the perceived criticality;

- to engage with privileged testimonials in the path of formal consultation with the participation in the forums (plenary and thematic).

A pilot action, with 5 electric cars and a small team of employees of the FUA of Correggio, started the 2nd of December 2011 and lasted 3 months, to test and improve the functionalities of the Mobility Management Office. The M.M. Office, recently created by the beneficiary "Agenzia della Mobilità”, is devoted to manage the IMOSMID integrated mobility system in the FUA of Correggio 
and namely the car pooling service with electric cars. The main goals, after the pilot action phase and until the end of the project, are:

- to involve a wider number of employees and companies belonging to the FUA of Correggio, in the use of the car pooling service;

- to activate the additional sustainable mobility measures agreed in the participatory process;

- to activate the Mobility Ticket Service to propel the rest of employees and citizens to do car pooling with their own cars.

\subsection{Outcomes/results achieved}

The obtained results are related to:

- a significant reduction of the number of vehicles that circulate within the district road network on a everyday basis: during the first 10 months of performing have been established 20 crews with 3-4 workers sharing the same vehicle for the "home -work" transport, that corresponds daily to 50-80 circulating cars less compared with the initial situation, i.e. at least 200,000 driven kilometres saved per year (Fig. 4);

- a substantial reduction of acoustic and pollutant emissions in the atmosphere; for example when it comes to carbon dioxide, the objective is to achieve a reduction of 20 tons per year (Fig. 4);
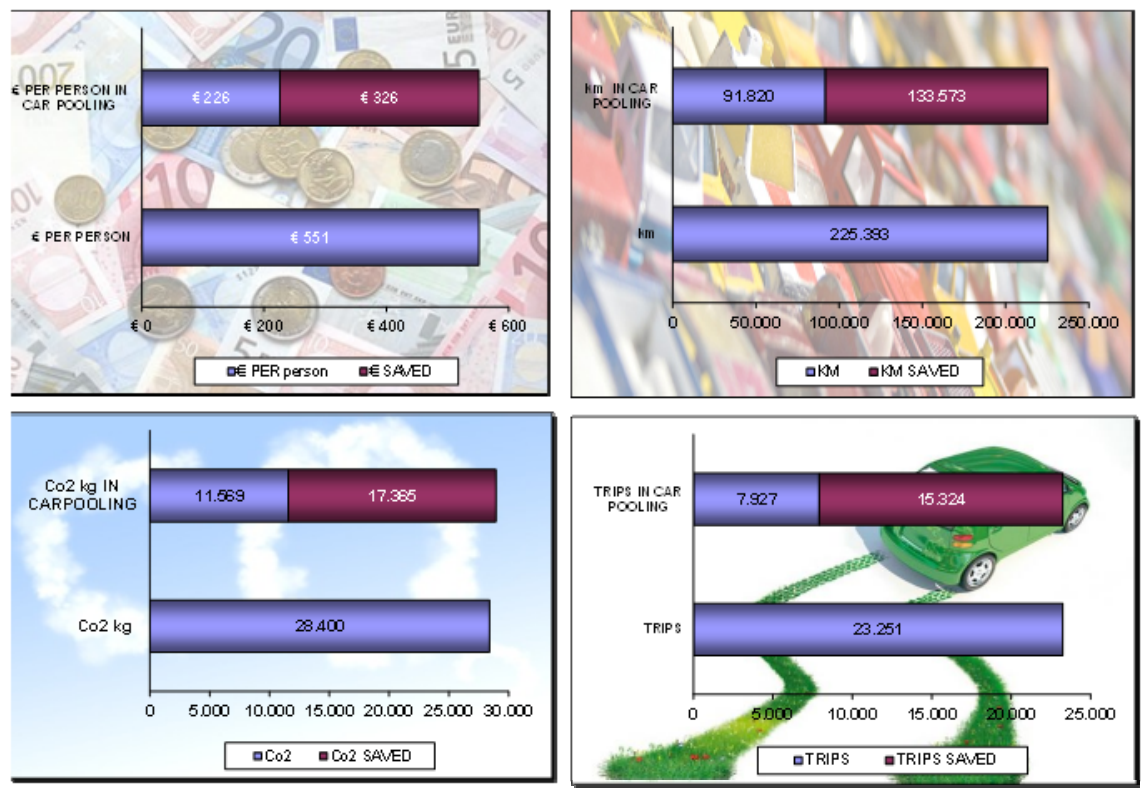

Figure 4: Results obtained after the first 10 months of performing the carpooling. 
- $\quad$ resulting benefits on traffic congestion since this reduction will occur during rush hour, which would lead to an improvement of the comfort's trips and a more fluid circulation on the road;

- a general reduction of road accidents number with advantage for motorists and pedestrians safety;

- a definition of a comprehensive methodology (analysis and project reports) and an assessment of the success/failure factors of the implemented measures (monitoring report) in order to define "good practice" feasible in similar contexts to concerned;

- a smart use of renewable energy locally produced (Fig. 5) to support commuters (the objective is to feed with renewable energy: at least 25 electric vehicles to be used for carpooling, up to a total of 50 electric vehicles (Fig. 5) for different uses);

- the project's effects - in terms of project legacy - will be long-lasting because the resources/know-how/knowledge/facilities listed below will remain on the territory even after the completion of the project:

$>$ the plant that produces energy from renewable sources (managed by En. Cor) designed to charge electric vehicles with a very low environmental impact totally free of charge;

$>$ the District Mobility Manager's Office, managed by the Agency and adequately organized (with tools/instruments, resources and expertise) for the wide development of home-work mobility;

$>$ the "ticket for a sustainable mobility" services.

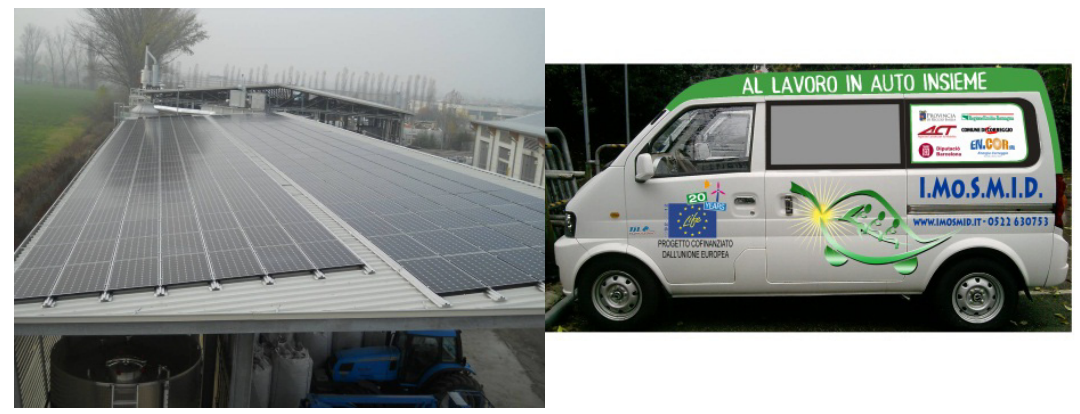

Figure 5: Photovoltaic shelters and electric vehicles used in the project.

\section{Conclusions}

The Project's approach is highly innovative providing original methods to integrated spatial planning including development of related survey, studies and project instruments. In the Project context, potential benefits of the involved new technologies will be a way to improve sustainable transport solutions, and they could serve to European regions and cities to define implementation plans, preferential population targets, partnerships between public and private sector, etc. On a specific level the conducted experiment in the District of Correggio 
will enable the activation of the "Air Quality's Protocol” that has been signed between Local Government Agencies and Business Associations in the Province of Reggio-Emilia, aiming at tackling the problem of environmental pollution and that includes, among its improving interventions, the promotion of integrated transport system. This project will promote the exchange of experiences, results and data in these fields among several domestic and European regions, with different degree of implementation of new technologies with the goal to serve as a platform to discuss approaches and methodologies, define best practices, transfer knowledge and experiences on how to tackle these complex issues at an interregional level, in order to achieve the maximum success and synergies among European regions. Other European, national and regional programmes and initiatives in this area could be also taken into account to assure the maximum diffusion and profit. This objective of improving the effectiveness of regional development policies, in the area of management models for people mobility using innovative technologies, through the exchange, sharing and transfer of policy experience, knowledge and good practices fulfils the overall objective of the LIFE+ Programme. An effective positive contribution can be achieved in promoting dedicated measures related to all the most efficient ways of using cars in order to achieve the following target areas:

Reducing demand for transport;

Enhancing energy efficiency in each transport mode;

Transfer of traffic to less energy intensive modes;

Economic instruments and incentives;

Information and awareness and education.

An additional Project's objective consists in to make citizenship aware of the effect of climate change. Built up a common and shared vision of common activities with different stakeholders (citizen: entrepreneurs, representatives NGO's, local leaders, councillors). Climate protection shall be funded as a social responsibility, in order to create new ways of framing the climate changes issue in order to translate passive awareness into active concern and to develop a network for educational tools for adult and youth people.

\section{Reference}

[1] Buzzoni, L., Meggs, J., Schweizer, J., ITACA HANDBOOK “Realizing Sustainable Mobility”, ITACA Project, POWER PROGRAMME, Brussels, Belgium, pp. 11-14, 2011. 